\title{
Gambaran Status Gingiva pada Anak Usia Sekolah Dasar di SD GMIM Tonsea Lama
}

\author{
${ }^{1}$ Cindra Ayu Apleine Karim, ${ }^{2}$ Paulina Gunawan, ${ }^{2}$ Dinar A. Wicaksono \\ ${ }^{1}$ Mahasiswa Program Studi Kedokteran Gigi Fakultas Kedokteran Universitas Sam Ratulangi \\ ${ }^{2}$ Dosen Program Studi Kedokteran Gigi Fakultas Kedokteran Universitas Sam Ratulangi
}

\begin{abstract}
ABSTRAK
Masa usia sekolah dasar adalah masa pertumbuhan gigi permanen yang menyebabkan perubahan pada gingiva sehingga meningkatkan resiko terjadinya inflamasi pada gingiva. Apabila kebersihan gigi dan mulut tidak terjaga, dapat meningkatkan resiko terjadinya inflamasi gingiva. Penelitian yang dilakukan merupakan jenis penelitian observasional dengan rancangan penelitian berupa penelitian deskriptif dengan menggunakan desain potong-lintang (cross sectional study). Tujuan dari penelitian ini yaitu untuk mengetahui gambaran status gingiva pada anak usia sekolah dasar. Penelitian dilakukan di SD GMIM Tonsea Lama dengan sampel siswa-siswi yang berusia 9 sampai 12 tahun sebanyak 47 orang. Pemeriksaan status gingiva dilakukan dengan menggunakan indeks gingiva. Hasil penelitian menunjukkan bahwa sebanyak 4 orang $(8,51 \%)$ memiliki gingiva sehat/normal, 30 orang $(63,83 \%)$ memiliki gingiva yang mengalami inflamasi ringan, 13 orang $(27,66 \%)$ memiliki gingiva yang mengalami inflamasi sedang, dan tidak ditemukan gingiva yang mengalami inflamasi berat.
\end{abstract}

Kata kunci : Usia sekolah dasar, status gingiva, indeks gingiva

\begin{abstract}
Elementary school age is a period of growth of permanent teeth that cause changes in gingival thus increasing the risk of inflammation in the gingival. In case the sanitary of teeth and mouth doesn't keep, it can increased gingival inflammation's risk. The research conducted with observational method by descriptive study design used cross sectional study. The main purpose for this research is to describe gingival status in elementary school's age. This research was conducted in GMIM Tonsea Lama Elementary School with 9 to 12 years old kids for the sample and amount 47 kids. Gingival status was checked using gingival's indeks. The results of the research showed that 4 kids (8,51\%) had healthy/normal gingival, $30 \mathrm{kids}(63,83 \%)$ had suffered mild gingival inflammation, 13 kids (27,66\%) had suffered moderate gingival inflammation, and there is no kids had suffered heavy gingival inflammation.
\end{abstract}

Keywords: elementary age, gingival status, gingival indeks

Koresponden: Cindra Ayu Apleine Karim, Program Studi Kedokteran Gigi Fakultas Kedokteran Universitas Sam Ratulangi. E-mail: cindra.karim20@yahoo.com

\section{PENDAHULUAN}

Gingiva ialah bagian dari mukosa mulut yang menutupi mahkota gigi yang tidak tumbuh dan mengelilingi leher gigi yang sudah tumbuh, berfungsi sebagai struktur penunjang untuk jaringan di dekatnya. Gingiva dibentuk oleh jaringan berwarna merah muda pucat yang melekat dengan kokoh pada tulang dan gigi, yang mukosa alveolar menyambung dengan mukogingival. ${ }^{1}$ Dalam istilah awam disebut gusi. ${ }^{2}$ Jika jaringan gingiva mengalami inflamasi maka disebut gingivitis.

Gingivitis terjadi karena kesehatan mulut yang tidak memadai yang biasanya ditandai dengan adanya kemerahan, bengkak dan kecenderungan pendarahan pada gingiva. ${ }^{3,45}$ Penyebab-penyebab lokal terjadinya gingivitis diantaranya deposit plak dan kalkulus di atas permukaan gigi, makanan yang terselip, gigi yang berlubang, restorasi tepi gigi yang menggantung, dan tambalan gigi yang tidak pas. ${ }^{6}$
Salah satu penelitian eksperimental tentang gingivitis menunjukkan bahwa akumulasi plak pada gingiva memiliki dampak yang sangat kuat dalam proses terjadinya gingivitis. ${ }^{7}$ Beberapa studi epidemiologimenunjukkan bahwagingivitisdari berbagai tingkat keparahanpada umumnya ditemukanpada anak-anakdan remaja. ${ }^{8}$ Prevalensi gingivitis pada anak-anak meningkat seiring dengan pertambahan usia hingga mencapai puncak pubertas. Prevalensi gingivitis pada anak-anak usia 5-14 tahun di Rajasthan (India) sekitar 84,37\%. ${ }^{9}$

Di Indonesia, gingivitis menduduki urutan kedua yaitu mencapai 96,58\%. Berdasarkan Riset Kesehatan Dasar (RISKESDAS) pada tahun 2007, masalah gigi dan mulut termasuk penyakit pada gingiva di Provinsi Sulawesi Utara yaitu sebesar $29,8 \% .{ }^{10} \mathrm{Pada}$ anak-anak, gingivitis tidak terjadi separah gingivitis pada orang dewasa. Hal ini dikarenakan perbedaan kuantitas dan kualitas plak bakteri, respon imun tubuh, ataupun perbedaan 
morfologi jaringan periodontium antara anak-anak dan orang dewasa. Plak bakteri pada anak-anak biasanya terdiri dari bakteri patogen yang konsentrasinya rendah. ${ }^{9}$ Namun, bila gingivitis pada anak dibiarkantanpaperawatan yang baik dan benar, dapat menimbulkanperiodontitis. ${ }^{4}$

Penelitian ini bertujuan untuk memperoleh gambaran tentang permasalahan gingiva pada siswa yang berada di SD GMIM Tonsea Lama.

\section{BAHAN DAN METODE}

Penelitian yang dilakukan merupakan jenis penelitian observasional dengan rancangan penelitian berupa penelitian deskriptif dengan menggunakan desain potong-lintang (cross sectional study). Penelitian ini dilakukan di SD GMIM Tonsea Lama, kecamatan Tondano Utara,kabupaten Minahasa pada bulan Agustus 2013.

Pada penelitian ini sampel yang digunakan yaitu siswa SD GMIM Tonsea Lama kelas 4, 5, dan 6 yang berusia 9 sampai 12 tahun dengan menggunakan teknik total sampling yaitu seluruh populasi yang berjumlah 53 orang dijadikan sebagai sampel.

Kondisi gingiva diukur menggunakan kaca mulut No. 4 dan probe periodontal dengan ujung berbentuk bola diameter $0,5 \mathrm{~mm}$, area berwarna hitam sebagai skala berada pada daerah $3,5-5,5 \mathrm{~mm}$ (probe periodontal $\mathrm{WHO}$ ) dengan cara menggerakkan probe periodontal pada setiap gigi indeks ke empat area gusi pada masing-masing gigi indeks (fasial, mesial, distal, dan lingual) dinilai tingkat inflamasinya dan diberi skor dari 0-3. Status gingiva diukur menggunakan indeks gingiva, yaitu : ${ }^{13}$

Skor 0 : Gingiva normal (tidak ada inflamasi, tidak ada perubahan warna, dan tidak ada peradangan)

1 : Inflamasi ringan (terlihat adasedikit perubahan warna dan sedikit edema tetapi tidak ada perdarahan saat probing)

2 : Inflamasi sedang (adanya warna kemerahan, adanya edema,dan terjadi perdarahan saat probing)

3 : Inflamasi berat (warna merah terang atau merah menyala, adanya edema, ulserasi, kecenderungan adanya perdarahan spontan)

Seluruh skor gigi dijumlahkan dan dibagi dengan jumlah gigi yang diperiksa, akan didapat skor indeks gingiva seseorang. ${ }^{11}$
Kriteria penilaian indeks gingiva $:^{11}$

$\begin{array}{ll}\text { Sehat } & : 0 \\ \text { Inflamasi ringan } & : 0,1-1,0 \\ \text { Inflamasi sedang } & : 1,1-2,0 \\ \text { Inflamasi berat } & : 2,1-3,0\end{array}$

\section{HASIL}

Berdasarkan hasil penelitian jumlah subjek yang sesuai dengan kriteria yaitu 47 orang dengan rentang usia antara 9 sampai 12 tahun (Tabel 1).

Tabel 1. Distribusi subjek penelitian berdasarkan usia

\begin{tabular}{ccc}
\hline Usia (Tahun) & Jumlah $(\mathbf{n})$ & Persentasi $(\%)$ \\
\hline 9 & 14 & 29,79 \\
10 & 15 & 31,91 \\
11 & 18 & 38,30 \\
12 & - & - \\
\hline Total & $\mathbf{4 7}$ & $\mathbf{1 0 0}$ \\
\hline
\end{tabular}

Berdasarkan usia dari siswa-siswi menunjukkan bahwa usia 9 tahun sebanyak 14 orang $(29,79 \%)$, usia 10 tahun sebanyak 15 orang $(31,91 \%)$, usia 11 tahun sebanyak 18 orang $(38,30 \%)$, dan tidak terdapat siswa yang berusia genap 12 tahun.

Tabel 2. Distribusi subjek penelitian berdasarkan jenis kelamin

\begin{tabular}{ccc}
\hline Jenis Kelamin & Jumlah (n) & Persentasi (\%) \\
\hline Laki-laki & 25 & 53,19 \\
Perempuan & 22 & 46,81 \\
\hline Total & $\mathbf{4 7}$ & $\mathbf{1 0 0}$ \\
\hline
\end{tabular}

Siswa-siswi SD GMIM Tonsea Lama yang memenuhi kriteria untuk dijadikan subjek dengan total 47 orang memiliki jumlah subjek yang berjenis laki-laki terbanyak yaitu 25 orang $(53,19 \%)$ dan 22 orang $(46,81 \%)$ yang berjenis kelamin perempuan.

Tabel 3. Distribusi status gingiva berdasarkan skor indeks gingiva

\begin{tabular}{cccc}
\hline Skor Indeks gingiva & $\begin{array}{c}\text { Jumlah } \\
(\mathbf{n})\end{array}$ & $\begin{array}{c}\text { Persentasi } \\
(\boldsymbol{\%})\end{array}$ & Ket \\
\hline 0 & 4 & 8,51 & Normal \\
$\begin{array}{c}\text { (Sehat) } \\
0,1-1,0\end{array}$ & 30 & 63,83 & Gingivitis \\
$\begin{array}{c}\text { (Inflamasi Ringan) } \\
1,1-2,0\end{array}$ & 13 & 27,66 & Gingivitis \\
$\begin{array}{c}\text { (Inflamasi Sedang) } \\
2,1-3,0\end{array}$ & - & - & Gingivitis \\
(Inflamasi Berat) & - & & \\
\hline
\end{tabular}


Pada penelitian ini, subjek yang memiliki gingiva normal 4 orang $(8,51 \%)$, inflamasi ringan sebanyak 30 orang $(63,83 \%)$,inflamasi sedang sebanyak 13 orang $(27,66 \%)$, dan ditemukan satupun siswa-siswi yang mengalami inflamasi berat.

Tabel 4. Distribusi status gingiva berdasarkan usia

\begin{tabular}{ccccc}
\hline & \multicolumn{4}{c}{ Skor Indeks Gingiva } \\
\cline { 2 - 5 } Usia & $\mathbf{0}$ & $\mathbf{0 , 1 - 1 , 0}$ & $\mathbf{1 , 1 - 2 , 0}$ & $\mathbf{2 , 1 - 3 , 0}$ \\
\cline { 2 - 5 } & $\mathbf{N \%}$ & $\mathbf{N \%}$ & $\mathbf{N \%}$ & $\mathbf{N \%}$ \\
\hline 9 & 12,13 & 1123,41 & 24,25 & - \\
10 & 24,25 & 1123,41 & 24,25 & - \\
11 & 12,13 & 817,01 & 919,16 & - \\
\hline Total & $\mathbf{4 8 , 5 1}$ & $\mathbf{3 0 6 3 , 8 3}$ & $\mathbf{1 3 2 7 , 6 6}$ & - \\
\hline
\end{tabular}

Data hasil penelitian yang didapatkan dari pemeriksaan status gingiva berdasarkan usia terlihat bahwa pada usia 9 tahun,1 orang $(2,13 \%)$ memiliki gingiva sehat/normal, 11 orang $(23,41 \%)$ inflamasi ringan, 2 orang $(4,25 \%)$ inflamasi sedang. Pada usia 10 tahun, 2 orang $(4,25 \%)$ memiliki gingiva sehat/normal, 11 orang $(23,41 \%)$ inflamasi ringan, 2 orang $(4,25 \%)$ inflamasi sedang. Pada usia 11 tahun, 1 orang $(2,13 \%)$ memiliki gingiva sehat/normal, 8 orang (17,01\%)inflamasi ringan, 9 orang $(19,16 \%)$ inflamasi sedang.

Tabel 5. Distribusi gingivitis berdasarkan usia

\begin{tabular}{|c|c|c|c|c|}
\hline \multirow{2}{*}{$\begin{array}{c}\text { Usia } \\
\text { (tahun) }\end{array}$} & \multicolumn{4}{|c|}{ Gingivitis } \\
\hline & Ada & $\%$ & Tidak Ada & $\%$ \\
\hline 9 & 13 & 27,66 & 1 & 2,13 \\
\hline 10 & 13 & 27,66 & 2 & 4,25 \\
\hline 11 & 17 & 36,17 & 1 & 2,13 \\
\hline Total & 43 & 91,49 & 4 & 8,51 \\
\hline $\begin{array}{l}\quad \text { Distribusi } \\
\text { menunjukkan } \\
\text { tahun, terdap } \\
\text { gingivitis, dar } \\
\text { gingivitis. Pa } \\
\text { terdapat } 13 \text { or } \\
2 \text { orang }(4,25 \\
\text { subjek yang }\end{array}$ & 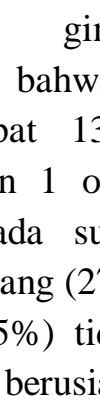 & $\begin{array}{l}\text { ivitis } \\
\text { pada } \\
\text { orang } \\
\text { ng }(2,1 \\
\text { jek yar }\end{array}$ & $\begin{array}{l}\text { berdasarkan } \\
\text { bjek yang b } \\
(27,66 \%) \mathrm{m} \\
\% \text { ) tidak m } \\
\text { berusia } 1\end{array}$ & $\begin{array}{r}\text { usia } \\
\text { erusia } 9 \\
\text { engalami } \\
\text { engalami } \\
\begin{array}{r}\text { tahun, } \\
\text { vitis dan } \\
\text { is. Pada }\end{array}\end{array}$ \\
\hline
\end{tabular}

$(36,17 \%)$ mengalami gingivitis dan 1 orang $(2,13 \%)$ tidak mengalami gingivitis.

Tabel 6. Distribusi gingivitis berdasarkan jenis kelamin

\begin{tabular}{ccccc}
\hline \multirow{2}{*}{$\begin{array}{c}\text { Jenis } \\
\text { Kelamin }\end{array}$} & \multicolumn{4}{c}{ Gingivitis } \\
\cline { 2 - 5 } & Ada & $\%$ & Tidak Ada & $\%$ \\
\hline Laki-laki & 25 & 53,19 & - & - \\
Perempuan & 18 & 38,30 & 4 & 8,51 \\
\hline Total & $\mathbf{4 3}$ & $\mathbf{9 1 , 4 9}$ & $\mathbf{4}$ & $\mathbf{8 , 5 1}$ \\
\hline
\end{tabular}

Tabel 6 menunjukkan bahwa seluruh subjek yang berjenis kelamin laki-laki mengalami gingivitis yaitu sebanyak 25 orang $(53,19 \%)$, pada subjek yang berjenis kelamin perempuan, terdapat 18 orang $(38,30 \%)$ mengalami gingivitis dan 4 orang $(8,51 \%)$ tidak mengalami gingivitis. Secara keseluruhan subjek yang mengalami gingivitis sebanyak 43 orang $(91,49 \%)$ dan subjek yang tidak mengalami gingivitis sebanyak 4 orang $(8,51 \%)$.

\section{PEMBAHASAN}

Batas usia yang digunakan untuk sampel penelitian yaitu 9 sampai 12 tahun. Penetapan usia yang digunakan dihitung berdasarkan terakhir kali subjek berulang tahun. ${ }^{12}$ Dari perhitungan penetapan usia yang digunakan, tidak terdapat subjek yang berusia 12 tahun, sehingga sampel yang didapatkan hanya berusia 9 sampai 11 tahun.Jumlah sampel penelitian yang memenuhi kriteria yaitu 47 orang.

Pada penelitian ini masalah gingiva paling banyak ditemui pada siswa yang berusia 11 tahun yaitu 17 orang $(36,17 \%)$. Hasil ini sesuai dengan penelitian yang dimuat ulang oleh Hafsari LS. (2003) menyatakan bahwa prevalensi gingivitisyang tertinggi adalah $90 \%$ pada anak dengan usia 11 tahun. Prevalensi gingivitis mengalami sedikit penurunan pada usia 11 sampai 17 tahun. ${ }^{13}$ Terjadinya penurunanprevalensigingivitis pada saat pertambahan usia mungkin disebabkan oleh berkurangnya akumulasi plak karena mulai timbulnya kepedulian dan pengetahuan untuk meningkatkan kebiasaan menyikat gigi.

Persentasi gingivitis pada penelitian ini lebih banyak ditemui pada laki-laki yaitu 25 orang $(53,19 \%)$ dibandingkan gingivitis pada perempuan yaitu 18 orang $(38,30 \%)$. Hasil ini sesuai dengan penelitian yang dilakukan di Pakistan oleh Nazir S. et 
al tahun 2010 pada 524 pasien gingivitis menunjukkan bahwa prevalensi penyakit gingiva jelas terlihat lebih banyak pada laki-laki dibandingkan perempuan, yaitu 71,18\% laki-laki dan $28,82 \%$ perempuan. ${ }^{14}$ Alasan dari hasil ini dikaitkan dengan tingkat kebersihan yang dinilai lebih tinggi pada perempuan. ${ }^{15}$ Adanya perbedaan tingkat kebersihan mulut pada siswa perempuan dan laki-laki terlihat jelas pada siswa SD GMIM Tonsea Lama yang menunjukkan lebih rendahnya penumpukkan plak pada siswa perempuan daripada laki-laki, dan dari pernyataan subjek siswa perempuan lebih banyak yang membersihkan gigi daripada siswa lakilaki.

Berdasarkan hasil penelitian terhadap siswa-siswi SD GMIM Tonsea Lama ini didapatkan bahwa persentasi sampel yang menderita gingivitis tinggi yaitu sebanyak 43 orang $(91,49 \%)$. Hasil ini diperkuat oleh penelitian yang dilakukan oleh Dwi Yanto pada salah satu sekolah dasar di Semarang yang menunjukkan bahwa prevalensi gingivitis pada anak tinggi yaitu 95,4\%. ${ }^{16}$ Pada penelitian ini ditemukan adanya penumpukan plak yang berlebih pada sebagian siswa yang diduga merupakan faktor penting terjadinya gingivitis. Hal ini disebabkan karena sebagian besar dari siswa belum memahami waktu dan cara membersihkan gigi yang tepat. Selain itu terdapat juga siswa yang menganggap bahwa hanya dengan berkumur sudah bisa membersihkan sisa makanan. Tidak adanya kepedulian dalam menjaga kebersihan gigi dan mulut dari siswa memberikan pengaruh besar dalam perkembangan bakteri plak yang terdapat di dalam mulut siswa yang menjadi subjek.

Plak gigi merupakan deposit lunak yang melekat erat pada permukaan gigi, terdiri atas mikroorganisme yang berkembang biak jika seseorang melalaikan kebersihan gigi dan mulutnya. ${ }^{11}$ Skor plak yang tinggi dapat dijumpai pada fase pertumbuhan gigi campuran, sebuah temuan yang sesuai dengan Ramberg. et al (1994) yang menyimpulkan bahwa terlihat jumlah plak yang banyak pada subjek yang mengalami fase gigi bercampur sehingga menyebabkan perubahan pada gingiva. ${ }^{17}$

Siswa-siswi yang menjadi sampel pada penelitian ini yaitu berusia 9 sampai 12 tahun yang berarti sudah berada pada fase pertumbuhan gigi campuran, sehingga tidak adanya pemahaman yang benar tentang pentingnya menjaga kebersihan gigi dan kurangnya informasi yang diberikan oleh tenaga kesehatan ataupun pengajar disekolah menyebabkan bertambah besarnya resiko terjadinya gingivitis pada penelitian ini.

\section{SIMPULAN}

1. Penyakit gingiva yang paling banyak ditemui yaitu pada kategori ringan, terbanyak kedua terdapat pada kategori sedang, dan tidak terdapat subjek yang mengalami masalah gingiva dengan kategori berat.

2. Penyakit gingiva paling banyak dijumpai pada siswa yang berusia 11 tahun.

\section{SARAN}

Siswa-siswi yang memiliki masalah pada gingiva agar lebih memperhatikan dan menjaga kesehatan gigi dan mulut dengan menyikat gigi secara teratur dan benar. Selain itu untuk siswa-siswi sudah memiliki kebiasaan baik tentang kesehatan gigi dan mulut agar dapat dipertahankan.

\section{DAFTAR PUSTAKA}

1. Dorland W.A. Newman. Kamus Kedokteran Dorland. $29^{\text {th }}$ ed. Jakarta: EGC; 2002. p. 914-5

2. Harty F.J, Ogston R. Kamus Kedokteran Gigi. Jakarta: EGC; 1995. p. 138

3. Mitchell RN, dkk. Buku saku dasar patologis penyakit. $7^{\text {th }}$ ed. Jakarta: EGC; 2008. p. 457

4. Riyanti E. Penatalaksanaan terkini gingivitis kronis pada anak. [serial online]. 2008 [cited 2013 April 27]; Available from URL: http://pustaka.unpad.ac.id/wpcontent/uploads/2010/06/penatalaksanaan terkini _gingivitis_kronis_pada_anak.pdf

5. Wiley J, Sons. Pediatric Dentistry, A Clinical Approach. $2^{\text {nd }}$ ed. Singapura: Wiley-Blackwell; 2009. p. 171

6. Adams GL, Boies LR, Higler PA. Boies buku ajar penyakit THT. $6^{\text {th }}$ ed. Jakarta: EGC; 1997. p. 27286

7. Lang NP, Schatzle MA, Loe H. Gingivitis as a risk factor in Periodontal disease. J Clin Periodontol 2009; 36 (suppl. 10): 3-8

8. Chauhan VS, Chauhan RS, Devkar N, Vibhute A, More S. Gingival and Periodontal disease in 
Children and Adolescents. Journal of Dental \& Allied Sciences 2012;1(1):26-29

9. Mitra M. Hubungan status karies dan gingivitis dengan oral hygiene pada Anak usia 6-12 tahun di Desa Ujung Rambung Kecamatan Pantai Cermin Kabupaten Serdang Bedagai. [serial online]. 2010 [cited 2013 Mei 5]; Available from URL: http://repository.usu.ac.id/bitstream/1234567 89/22644/5/Chapter\%20I.pdf

10.Anonimous. Riset Kesehatan Dasar (RISKESDAS) 2007. Laporan Nasional. Departemen Kesehatan Republik Indonesia;2008. p. 130-2 [cited 2013 Mei 1]; Available from URL: http:www.scribd.com/doc/82922543/laporan Nasional-Riskesdas-2007

11.Putri MH, Herijulianti E, Nurjannah N. Ilmu pencegahan penyakit Jaringan Keras dan Jaringan Pendukung Gigi. Jakarta: EGC; 2010 p. 26-35, 196-9

12.Anonimous. Karakteristik penduduk. Data statistik Indonesia;2013. p.1 [cited 2013 September 28]; Available from URL: http://www.datastatistik-indonesia.com/portal

13. Hafsari LS. Perawatan dasar gingivitis pada anak. [serial online]. 2003 [cited 2013 Agustus 30]; Available from URL: http://repository.usu.ac.id/bitstream/1234567 89/8288/1/960600037.pdf
14.Hiremath V, Mishra N, Patil AG, Sheetal A, Kumar S. Prevalence of gingivitis among children living in Bhopal. J Oral Health Comm Dent 2012;6(3)118-120. [cited 2013 September 25]; Available from URL: http://www.johcd.org/pdf/Sept_Dec2012/03 JOHCD\%20(Prevalence\%20of\%20gingivitis $\% 20$ among\%20children)\%20(2).pdf

15.Nazir S, Arain AH. Gender specific prevalence of gingival disease among the patients visiting Baqai Dental Hospital. Pakistan Oral \& Dental Journal 2010;30(2). [cited 2013 September 24]; Available from URL: http://www.podj.com.pk/Dec 2010/48PODJ.pdf

16. Yatno D. Survei prevalensi gingivitis pada anak sekolah dasar kelas V dan VI di Desa Kradenan Kecamatan Susukan Kabupaten Semarang. [serial online]. 2003 [cited 2013 September 23]; Available from URL: http://www.fkm.undip.ac.id/data/index.php?a ction $=4 \& \mathrm{idx}=802$

17.Safii SH, Shoaib LA, Awang H. Pattern of caries and gingivitis in a selected population of schoolchildren aged 9 to 11 years. Sains Malaysiana 42(1)(2013): 107-114. [cited 2013 September 24]; Available from URL: http://www.ukm.my/jsm/pdf_files/SM-PDF$\underline{42-1-2013 / 18 \% 20 \text { Syarida.pdf }}$ 